\title{
A Model for Multiseasonal Spread of Verticillium Wilt of Lettuce
}

\author{
B. M. Wu and K. V. Subbarao
}

First author: Department of Plant Pathology, China Agricultural University, Beijing 100193; and second author: Department of Plant Pathology, University of California-Davis, c/o U.S. Agricultural Research Station, 1636 E. Alisal Street, Salinas, CA 93905. Accepted for publication 24 February 2014.

\section{ABSTRACT}

Wu, B. M., and Subbarao, K. V. 2014. A model for multiseasonal spread of Verticillium wilt of lettuce. Phytopathology 104:908-917.

Verticillium wilt, caused by Verticillium dahliae, is a destructive disease in lettuce, and the pathogen is seedborne. Even though maximum seed infestation rates of $<5 \%$ have been detected in commercial lettuce seed lots, it is necessary to establish acceptable contamination thresholds to prevent introduction and establishment of the pathogen in lettuce production fields. However, introduction of inoculum into lettuce fields for experimental purposes to determine its long term effects is undesirable. Therefore, we constructed a simulation model to study the spread of Verticillium wilt following pathogen introduction from seed. The model consists of four components: the first for simulating infection of host plants, the second for simulating reproduction of microsclerotia on diseased plants, the third for simulating the survival of microsclerotia, and the fourth for simulating the dispersal of microsclerotia. The simulation results demonstrated that the inoculum density-disease incidence curve parameters and the dispersal gradients affect disease spread in the field. Although a steep dispersal gradient facilitated the establishment of the disease in a new field with a low inoculum density, a long-tail gradient allowed microsclerotia to be dispersed over greater distances, promoting the disease spread in fields with high inoculum density. The simulation results also revealed the importance of avoiding successive lettuce crops in the same field, reducing survival rate of microsclerotia between crops, and the need for breeding resistance against $V$. dahliae in lettuce cultivars to lower the number of microsclerotia formed on each diseased plant. The simulation results, however, suggested that, even with a low seed infestation rate, the pathogen would eventually become established if susceptible lettuce cultivars were grown consecutively in the same field for many years. A threshold for seed infestation can be established only when two of the three drivers of the disease-(i) low microsclerotia production per diseased plant, (ii) long-tail dispersal gradient, and (iii) low microsclerotia survival between lettuce crops-are present.
Multicyclic foliar diseases such as wheat stripe rust and potato late blight progress quickly and cause severe yield losses rapidly in a cropping season (8). Such diseases are amenable for modeling because studies to calculate the various components of the model and the corresponding parameters for the pathogen and the host can be completed in a relatively short time. Thus, the majority of modeling studies have emphasized diseases caused by foliar pathogens and most of the models constructed also are represented by such diseases (8). Soilborne diseases, in contrast, and especially those caused by vascular wilt pathogens, typically are monocyclic, and secondary infection seldom occurs within a cropping season $(18,30,33,47)$. The propagules produced by soilborne pathogens often are transported over relatively short distances and usually survive in soil for prolonged periods (45). Relative to the diseases caused by airborne plant pathogens, the progress of soilborne diseases (except those such as damping-off and other root rot diseases) is slower and follows a monomolecular model within a cropping season. However, disease problems worsen over time because pathogen propagules accumulate in soil when the host crop is repeatedly grown in a field (38). This property of protracted disease progress has made the study of soilborne disease spread more difficult. The persistence of propagules in soil renders the introduction of artificial inoculum into experimental fields undesirable. These difficulties are reflected in the limited modeling efforts on soilborne diseases. Despite these difficulties, some classic modeling work has been done on Rhizomania of sugar beet caused by Beet necrotic yellow vein virus, which is transmitted by Polymyxa betae (15). Both the

Corresponding author: K. V. Subbarao; E-mail address: kvsubbarao@ucdavis.edu

http://dx.doi.org/10.1094/PHYTO-12-13-0333-R

(C) 2014 The American Phytopathological Society vector and the pathogen can persist in the soil for up to 30 years, and eradication of the pathogen from soil is impractical. Therefore, transmission between fields and farms occurs mainly by agricultural implements during land preparation, cultivation, and harvest. Even though the virus can readily infect sugar beet, the symptoms are not expressed until the threshold density of the viruliferous vector is reached. This can take up to 15 years from initial infestation of the field to symptom appearance on sugar beet (15). Modeling of soilborne diseases otherwise has mainly been focused on predicting disease levels within a cropping season based on the weather conditions, inoculum density, and other factors (35), whereas very little has been done on multiple seasonal spread and disease progress.

Verticillium wilts are important vascular wilt diseases that affect many crops and ornamentals in different regions of the world. The disease is most important in temperate regions, occurs less frequently in the subtropics, and is rare in tropical regions of the world $(21,22,31)$. Economic losses of $\geq 50 \%$ commonly occur on high-value crops, including cotton (14), lettuce $(3,41)$, and potato (36). In strawberry without soil fumigation, losses of up to $75 \%$ have been recorded (46). Many more important crops and ornamentals (31) are affected but precise loss estimates are not readily available.

Although 10 species are capable of causing Verticillium wilts (22), the species that causes the most damage is Verticillium dahliae. Verticillium dahliae survives by means of resting structures called microsclerotia that can remain viable for up to 14 years (45). The disease becomes a major problem when the density of microsclerotia reaches high levels $(1,2,5,17,20,32$, $33,40,47)$. Characteristically, $V$. dahliae is a nonaggressive soil resident, which seldom ventures more than a few millimeters from its propagule base in the absence of tillage and other field operations. Host infections are initiated upon germination of the 
resting structures and are followed by penetration into roots, slow progression through the vasculature, and entry into the shoots (13). Once the pathogen reaches the xylem, it becomes systemic within the vascular system (43). Distinct external symptoms, including wilting and tissue necrosis, typically appear only near the end of the disease cycle and often coincide with host maturity (23). The disease is typically monocyclic and, thus far, secondary infection has not been detected within a season (18).

Lettuce was not a host of $V$. dahliae until the mid-1990s but Verticillium wilt has now become a major problem for coolseason lettuce production in coastal California. The total number of affected fields since the disease was first described in 1995 (39) increased to $>150$ by the end of 2010 (3). Losses from Verticillium wilt often exceeds $90 \%$ in lettuce (39). The disease has only been associated with soil microsclerotial densities of $>150 \mathrm{~g}^{-1}$ of soil, and microsclerotial density as high as $2,500 \mathrm{~g}^{-1}$ of soil has been documented in fields where the disease was first discovered (3).

The seedborne nature of $V$. dahliae in some crops has long been recognized $(10,43)$ but, through the employment of a green fluorescent protein-tagged isolate of $V$. dahliae, Vallad and Subbarao (43) first documented the pathogen growth into the inflorescence and the developing seed. Vallad et al. (42) also showed that $V$. dahliae could persist $>72$ weeks when seed were stored at low temperature $\left(\leq 15^{\circ} \mathrm{C}\right)$, and the incidence of Verticillium wilt could be as high as 55 to $80 \%$ among the lettuce plants grown from infested seed (42). However, evaluation of commercial lettuce seed lots over multiple years detected $<5 \%$ seed infestation by $V$. dahliae (3). If infested lettuce seed is the sole source of primary inoculum, it is desirable to investigate the threshold level of seed contamination that impedes the establishment and buildup of $V$. dahliae microsclerotia in soil and prevents epidemics of Verticillium wilt on lettuce. It would take many years of field experimentation to determine the duration over which the threshold inoculum density required for high disease incidence would be reached with the different seed infestation levels.

Therefore, the goals of this investigation were to construct a conceptual simulation model for the spread of the disease in the field, and to provide simulation results to support decisionmaking as it relates to the management of Verticillium wilt in lettuce production. The specific objectives of this study were to (i) construct a stochastic model for the spread of Verticillium wilt over multiple lettuce crops; (ii) identify the critical factors that affect epidemics of Verticillium wilt in lettuce, such as the effects of parameters related to the production, dispersal, and survival of microsclerotia, and infection of plants by the pathogen; and (iii) assess the risk of Verticillium wilt initiated from contaminated seed with different infestation rates and under different production systems (one or two lettuce crops per year) to provide a tentative tolerance threshold of $V$. dahliae in commercial lettuce seed.

\section{THEORY AND APPROACHES}

The model consists of four components: (i) infection of host plants by germinating microsclerotia, (ii) reproduction of microsclerotia on diseased plants, (iii) survival of microsclerotia, and (iv) dispersal of microsclerotia (Fig. 1).

Infection of host plants by germinating microsclerotia. Verticillium wilt is typically a monocyclic disease (18). Soilborne microsclerotia are the primary inoculum for infection. There is no secondary infection or plant-to-plant spread within a cropping season (48). Therefore, disease incidence is directly related to the magnitude of viable inoculum in the soil, efficacy of the initial inoculum, and the length of time the host is in contact with the pathogen, even though ambient weather as well as soil conditions play a vital role in some crops (16). The inoculum density- disease incidence (ID-DI) relationship can be fitted to a negative exponential model in many cropping systems. Pullman and DeVay (33) found that the inoculum density of $V$. dahliae in May was related to mid-September foliar wilt incidence in cotton, and that the slope of ID-DI curve declined as the inoculum density increased. Harris and Yang (20) determined that the relationship between wilt incidence on strawberry and inoculum density of $V$. dahliae in the soil can be fitted to a linear regression model after multiple infection transformation and that as few as 2 microsclerotia $\mathrm{g}^{-1}$ of soil can cause up to $50 \%$ wilt incidence. Xiao and Subbarao (47) established that wilt incidence and severity on cauliflower increased with increasing inoculum density of up to $\approx 20$ microsclerotia $\mathrm{g}^{-1}$ of soil, and a negative exponential model described the ID-DI relationships under both microplot and field conditions. The relationship between inoculum density of $V$. dahliae and wilt incidence in artichoke in Spain also followed a negative exponential model (5).

The in-season disease progress and the time of infection are not considered in the current version of the model. The only output of the model is the final incidence of wilt. For the first lettuce crop, assuming that infested seed is the only inoculum source, the model simulates the disease incidence based on the rate of infested seed. For the second and the subsequent lettuce crops, the incidence of Verticillium wilt is estimated from the viable inoculum density in soil at planting according to a standard ID-DI curve. Because the ID-DI relationship had not been established for Verticillium wilt in lettuce prior to this study, an ID-DI curve was fitted to the survey data obtained over many years. Commercial lettuce fields in the Salinas and Pajaro Valleys were surveyed

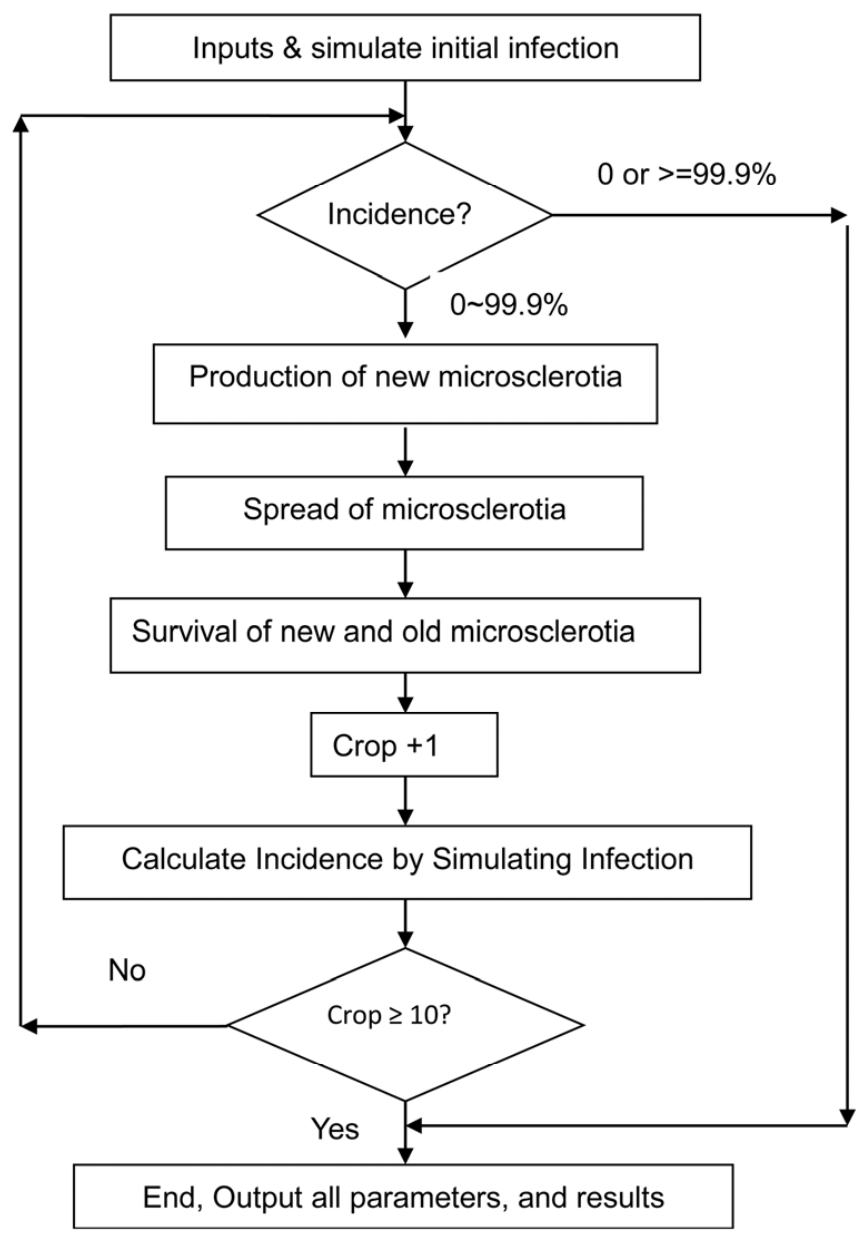

Fig. 1. Structure of the simulation model for the spread of Verticillium wilt in lettuce. If disease incidence is 0 or $\geq 99.99$, or the number of crops simulated is $\geq 10$, the simulation will end to shorten computing time. 
for incidence of Verticillium wilt since the disease was first discovered in 1995. Each field was walked in an X pattern and, at 20 randomly chosen $2-$ by-2-m areas along the transect, the number of plants and the number diseased plants were counted, and disease incidence expressed as a percentage of the total plants was calculated. Soil samples were also collected from the top $15 \mathrm{~cm}$ of the soil profile from the locations where incidence data were collected and assayed for microsclerotia of $V$. dahliae by plating the pulverized soil on NP-10 medium using the modified Anderson sampler technique (7). The results indicated that the development of Verticillium wilt on lettuce was exclusively associated with inoculum densities of $>100 \mathrm{~V}$. dahliae $\mathrm{CFU} \mathrm{g}^{-1}$ of soil in the field. Although the minimum number of microsclerotia in soil required to cause wilt varies with cropping systems, such high inoculum densities of $V$. dahliae are rare in crops other than lettuce. For example, the inoculum density required to cause 5\% wilt incidence was estimated as $0.1 \mathrm{CFU} / \mathrm{g}$ of soil for cotton (2), 0.32 to $1.90 \mathrm{CFU} / \mathrm{g}$ of soil for strawberry (20), and $1.0 \mathrm{CFU} / \mathrm{g}$ of soil in cauliflower (47). A density of 5 to $30 \mathrm{microsclerotia} / \mathrm{cm}^{3}$ of soil was adequate to cause significant disease in potato (32), 0.5 to $1 \mathrm{CFU} \mathrm{g}^{-1}$ of soil was associated with economic damage in peppermint (40), and $1.0 \mathrm{CFU} \mathrm{g}^{-1}$ of soil resulted in nearly $15 \%$ wilt incidence at the end of the first season in artichoke in the Valencia Region of Spain (5). The results from surveys suggested that lettuce is unique with its requirement of a significantly higher density of microsclerotia in soil for Verticillium wilt development than all other crops in which the disease is a problem. Therefore, instead of a negative exponential model, a logistic model (disease incidence $=100-100 /[1+\exp (r \times$ inoculum density $-a)])$ with two parameters, growth rate $r$ and threshold $a$, was fitted to the survey data (Fig. 2) using the nonlinear regression procedure in SAS (version 9.2; SAS Institute Inc., Cary, NC). The 95\% confidence interval of parameters $a$ and $r$ were estimated as 4.62 to 5.70 (best estimate 5.16) and 0.0285 to 0.0352 (best estimate $0.0319)$, respectively. Based on the $95 \%$ confidence band of IDDI curve, the inoculum density required for $5 \%$ disease incidence was estimated to be between 49 and $98 \mathrm{CFU} \mathrm{g}^{-1}$ of soil (Fig. 2).

Reproduction of microsclerotia on diseased plants. The number of microsclerotia produced on each plant infected by $V$. dahliae is crop-specific and varies with resistance in the host, time of infection, and environmental conditions. McIntyre and

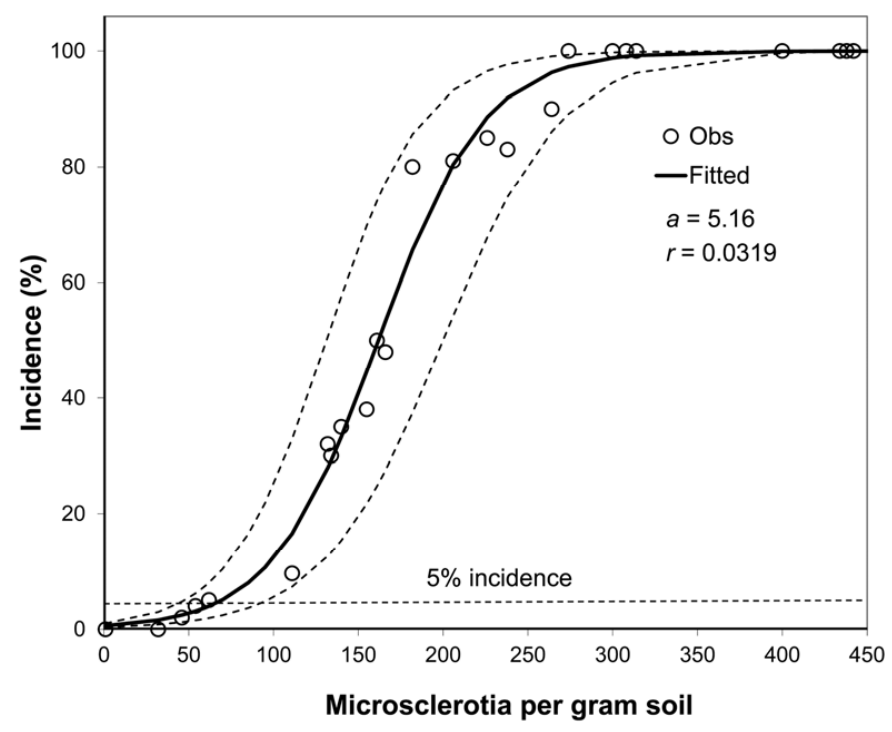

Fig. 2. Relationship between inoculum density (microsclerotia [ms]/g of soil) and disease incidence for Verticillium wilt in lettuce. Circles are data from surveys in commercial lettuce fields in the Salinas Valley, and the dashed lines are the $95 \%$ confidence interval band for fitted models $\left[1-1 /\left(1+e^{\mathrm{r} \cdot \mathrm{ms}-\mathrm{a}}\right)\right]$ with parameters rate $r$ and threshold $a$.
Horner (28) reported an average of 250,000 to $1,250,000$ CFU of $V$. dahliae in a gram of peppermint stem tissue. Brandt et al. (6) recovered 100 to 15,000 propagules $/ \mathrm{ml}$ of infected stem from susceptible mint (Mentha piperita) plants but mostly $<10$ propagules from resistant $M$. crispa plants (6). Mol and Scholte (29) determined that the petiole and the aerial stem of potato contributed most to the total microsclerotia, whereas roots contributed more than stolons among the subterranean parts (29). The highest numbers of microsclerotia were observed in the haulm at potato harvest, with significantly more microsclerotia of $V$. dahliae formed in the haulm of cultivar 'Element' than in 'Mirka' (29). Erwin et al. (11) reported $V$. dahliae at $\approx 35,000 \mathrm{CFU} \mathrm{g}^{-1}$ of

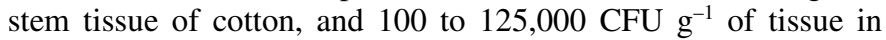
leaves and petioles of infected cotton (11).

As for lettuce, Vallad and Subbarao (43) recovered $V$. dahliae, on average, at 513 and 1,023 $\mathrm{CFU} \mathrm{g}^{-1}$ (fresh weight) of infected taproots of susceptible lettuce 'Salinas' in two independent experiments, whereas the numbers for resistant 'La Brillante' were

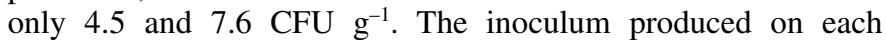
infected plant varied also widely with the disease severity. From dead lettuce plants (with a severity of 5 on a scale of 0 to 5), 2,570 to $107,152 \mathrm{CFU}$ of $V$. dahliae was recovered from a gram of infected taproot (43). Assuming that the average fresh weight of a taproot was $50 \mathrm{~g}$, this would translate to $\approx 1.3$ to 5.4 million microsclerotia from each taproot in addition to microsclerotia produced in the crown and leaves. The effects of these large numbers of microsclerotia produced on infected plants was also validated by the six-fold increase in the density of microsclerotia in soil from the appearance of symptoms to the time after harvest and tillage (3).

We assumed that the log transformed number of microsclerotia produced on each diseased plant is a random number following the normal distribution. In a simulation of microsclerotia production, a random number msnumber following a normal distribution with a mean between 6 and 6.7 and standard deviation 0.12 was first generated for each infected lettuce plant and then the number of microsclerotia was calculated via reverse log transformation: $M S_{\text {production }}=10^{\mathrm{msnumber}}$.

Survival of microsclerotia. Microsclerotia of $V$. dahliae are reported to survive for up to 14 years in the soil (37). Studies on soilborne fungal pathogens suggested that soil temperature, soil moisture and the length of burial period are the major factors determining the survival of fungal propagules $(9,16)$. Green $(16)$ reported that the combination of high temperature and high moisture resulted in the lowest survival of microsclerotia that also varied with soil types. Because soil temperature and moisture are usually optimal to lettuce production in the Salinas Valley, with very limited seasonal variations and even less variation among years, we assumed that the survival of microsclerotia in soil varies more with the length of soil retention than with the environmental conditions in the soil. In central costal California, where Verticillium wilt is a threat to lettuce production, lettuce can be grown either one crop (spring or fall crop) a year or two crops (spring and fall crops) a year. In this study, we considered survival of microsclerotia between two lettuce crops and during lettucegrowing seasons. First, microsclerotia produced on infected lettuce plants need to survive through a no-lettuce period to infect lettuce plants in the subsequent crops.

In the two-crops-per-year system, the spring-to-fall crop-free period usually lasts only a few weeks and the fall-to-spring cropfree period is usually a few months. Therefore, the survival rate of microsclerotia over the spring-to-fall period $\left(S_{2 a}\right)$, which is usually shorter and warmer, should be comparable with the survival rate over the fall-to-spring period $\left(S_{2 b}\right)$, which is slightly longer but colder. To simplify simulation, we assigned a constant survival rate of microsclerotia for both intervals in the two-cropsper-year system over multiple years. In the one-crop-a-year system, the lettuce-free period usually lasts $\approx 9$ months, equal to the 
spring-to-fall gap plus fall-to-spring gap and a lettuce-growing season.

Some microsclerotia produced from infected plants may not infect plants in the very next lettuce crop; instead, they survive in the soil through the cropping season and become an inoculum source for subsequent crops. A cropping season is $\approx 3$ months, slightly longer for spring than for fall crops. Regardless of the preceding history of microsclerotia, we assigned the same survival rate $\left(S_{c}\right)$ to all the viable microsclerotia for both spring and fall crops in this model because we assumed that the small differences in the duration and soil environmental conditions between the two cropping seasons have little effect on the survival of $V$. dahliae.

Assuming that the survival of microsclerotia is independent of the history of microsclerotia (or follows an exponential decay model), we can also deduce that the survival rate over the nolettuce gap $\left(S_{1}\right)$ can be calculated from $S_{2 a}, S_{2 b}$, and $S_{c}: S_{1}=S_{2 a}$. $S_{2 b} \cdot S_{c}$ (2). Because $S_{2 a}, S_{2 b}$, and $S_{c}$ are all $<100 \%$, it is obvious that $S_{I}$ is smaller than $S_{2 a}$ and $S_{2 b}$. To simplify the simulation, we assumed that the difference between the two cropping systems is mainly the survival rate of microsclerotia during the no-lettuce period between lettuce crops in this simulation model.

Carlstrom (9), Farley et al. (12), and Green (16) all reported an increase in soilborne propagules of $V$. dahliae shortly after the incorporation of plant debris, and they attributed the increase to either sporulation or further release in the number of microsclerotia helped by the decomposition of plant debris. However, we did not consider this change in this study because the timing of infection is not considered in the current version of the simulation model and the number of microsclerotia produced on each plant is only a theoretical number and may be greater than the number determined from actual plating.

Dispersal of microsclerotia. Dissemination of $V$. dahliae over a long distance is usually accomplished via plant materials such as potato tubers, peppermint roots, lettuce and spinach seed, and so on. Fungus gnats and other insects have also been implicated in the transmission of spores of $V$. albo-atrum $(=V$. nonalfalfae) $(22,26)$ but the role of insects in the spread of $V$. dahliae remains unclear. Surface running water and wind carrying soil dust or plant debris also can spread microsclerotia of $V$. dahliae. The spread of $V$. dahliae within a field can also occur from tillage operations such as soil disking, ripping, plowing, chiseling, land planing, and so on that move soil or plant debris, as well as by personnel during harvest. Because these field operations usually follow the row direction, the spatial pattern of microsclerotia of $V$. dahliae and subsequent incidence of Verticillium wilt have often been reported to be aggregated over a longer distance along the row directions than across rows, such as in the cauliflower fields of California (48) and in mint in Washington (25). In both cases, the distance (influence range) over which the wilt incidence or microsclerotia were aggregated was relatively small and no more than a few meters. In the current simulation model, we assumed that both in-row and across-row dispersal of microsclerotia independently follow the power law model $\mathrm{ms}_{0} \cdot \alpha^{-\mathrm{d}}$ and $\mathrm{ms}_{0} \cdot \beta^{-\mathrm{d}}$.
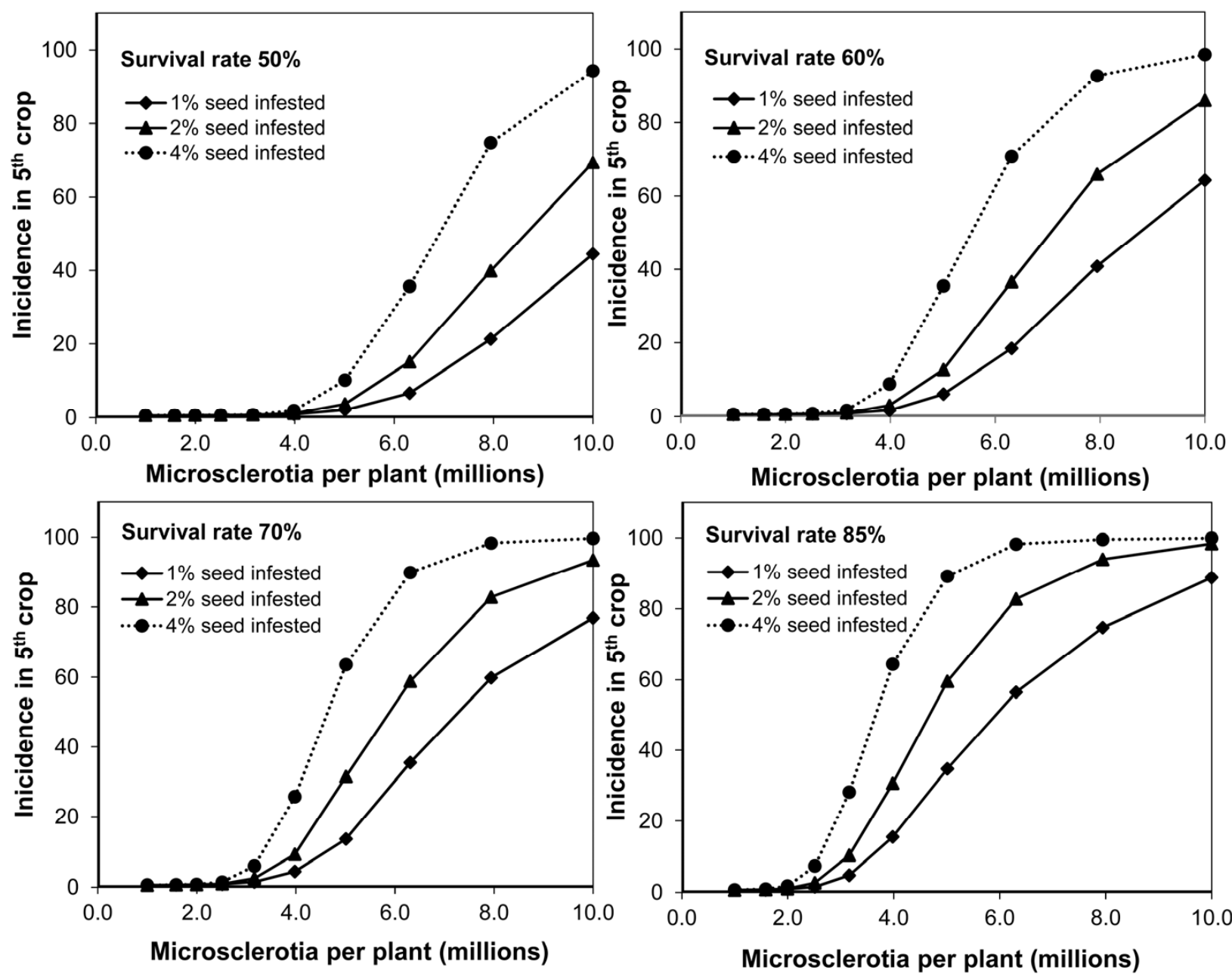

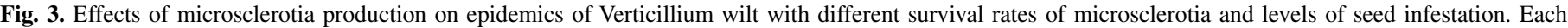

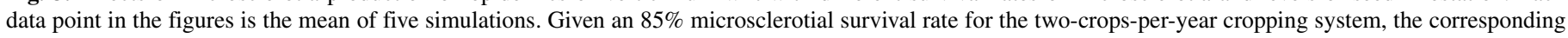
survival rate would be 50 to $60 \%$ for the one-crop-per-year system. 
Microsclerotia at any particular spot will be the result of in-row and across row dispersal together: $m s=\mathrm{ms}_{0} \cdot \alpha^{-\mathrm{dx}} \cdot \beta^{-\mathrm{dy}}$. To reduce computation time during simulation, the model only simulated the distribution of microsclerotia of $V$. dahliae over 15 rows across and 30 plants along the row direction because the influence range is short for the disease $(25,48)$.

\section{RESULTS}

Responses to microsclerotia production. Generally, the more microsclerotia produced per diseased plant, the faster the microsclerotia density increased, and the faster the wilt incidence increased in crops over different seasons. When the model was run with the best fitted ID-DI parameters ( $r=0.0319$ and $a=5.16)$ together with the dispersal gradient parameters of $\alpha=3.6$ and $\beta=$ 1.8 , the number of microsclerotia formed on each diseased plant played a very important role in all cases, with different survival rates of microsclerotia between crops (which is likely to be $85 \%$ for the two-crops-per-year system and 50 to $60 \%$ for one-cropper-year system) and different initial seed infestation levels (Fig. 3 ). For example, in a two-crops-per-year system with a survival rate of $85 \%$, the wilt incidence can increase to $34.8 \%$ for the initial $1 \%$ seed infestation within five crops (which is just twoand-a-half years) at 5 million microsclerotia per diseased plant. The Verticillium wilt epidemics on lettuce can be slowed down significantly if the microsclerotia produced on each plant can be reduced to 2 million. Under such a scenario, $<1 \%$ wilt occurs on the fifth lettuce crop (Fig. 3). These numbers would be 59.5 versus $1.0 \%$ and 89.1 versus $1.8 \%$ if the initial level of seed infestation was 2 and $4 \%$, respectively.

When the number of newly produced microsclerotia that are added to the soil is less than the threshold required for Verticillium wilt development on lettuce, the disease cannot become established in the field. The threshold is dependent on other parameters, such as survival rate, ID-DI relationship, and the survival rate of microsclerotia between lettuce crops (which varies with the number of crops per year). For example, if the pathogen forms $\leq 1.0$ million microsclerotia on each diseased plant, the incidence of Verticillium wilt in the fifth lettuce crop is always $<1 \%$ under all different conditions simulated (Fig. 3).

Response to the survival rate of microsclerotia. The survival rate determines how many microsclerotia could be carried over from a crop to the subsequent crops and cause infections on these crops. The greater the survival rate of microsclerotia, the faster is the increase in disease incidence (Fig. 4). When the number of microsclerotia produced per diseased plant is $\leq 1.0$ million, the disease seldom becomes an epidemic regardless of the survival rate or the initial seed infestation level in the range tested (Fig. 4A). When the pathogen forms 2.0 to 5.0 million microsclerotia on a diseased plant, the increase in the survival rate makes a large difference (Fig. 4B and C). However, when the pathogen forms 10.0 million microsclerotia on a diseased plant and the initial seed infestation is $\geq 4 \%$, the higher survival rate does not result in a rapid increase in disease incidence because multiple infection

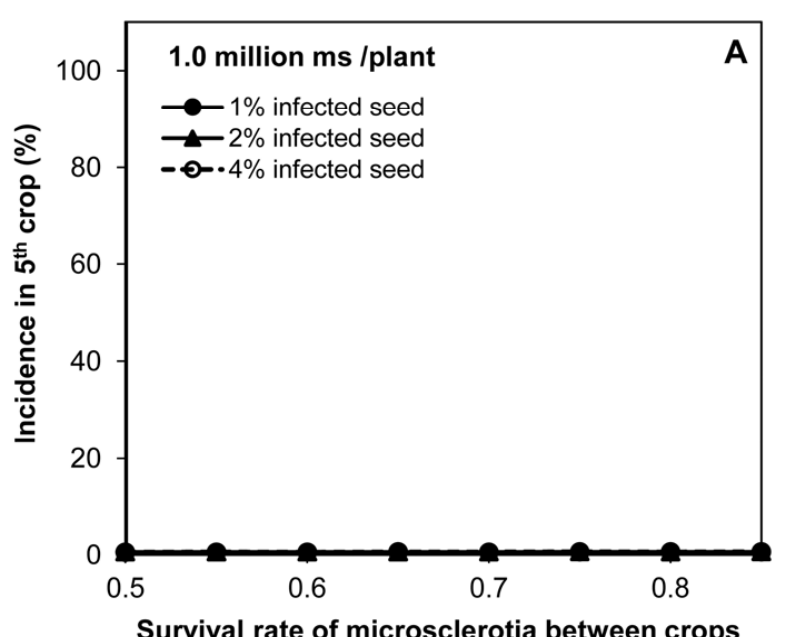

Survival rate of microsclerotia between crops

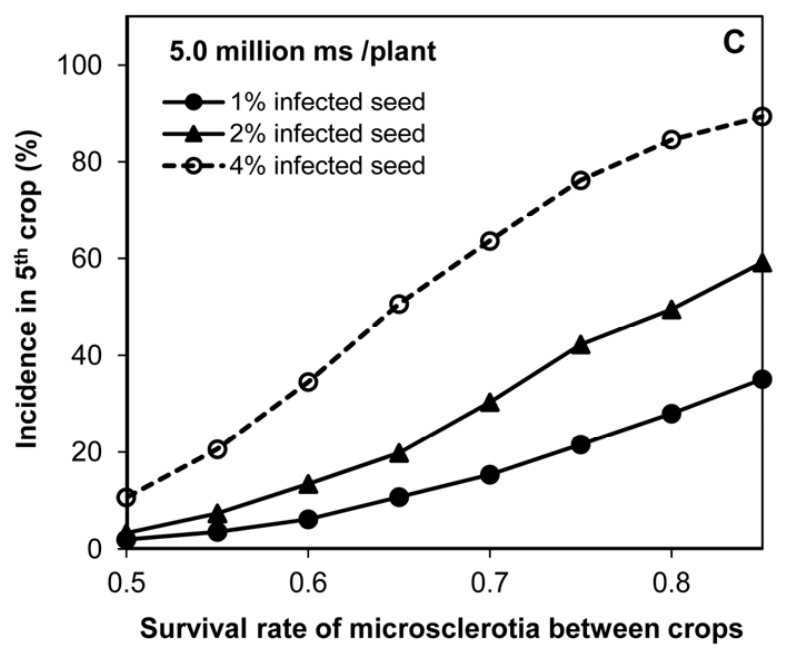

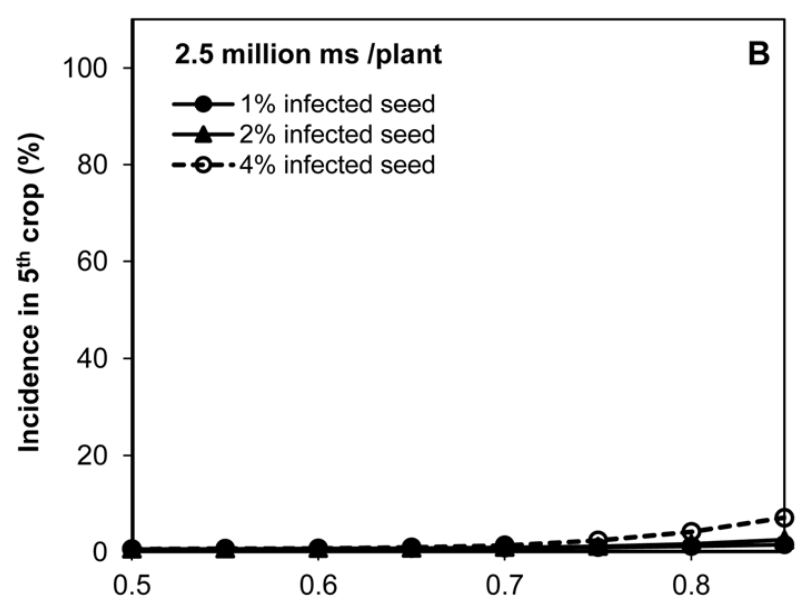

Survival rate of microsclerotia between crops

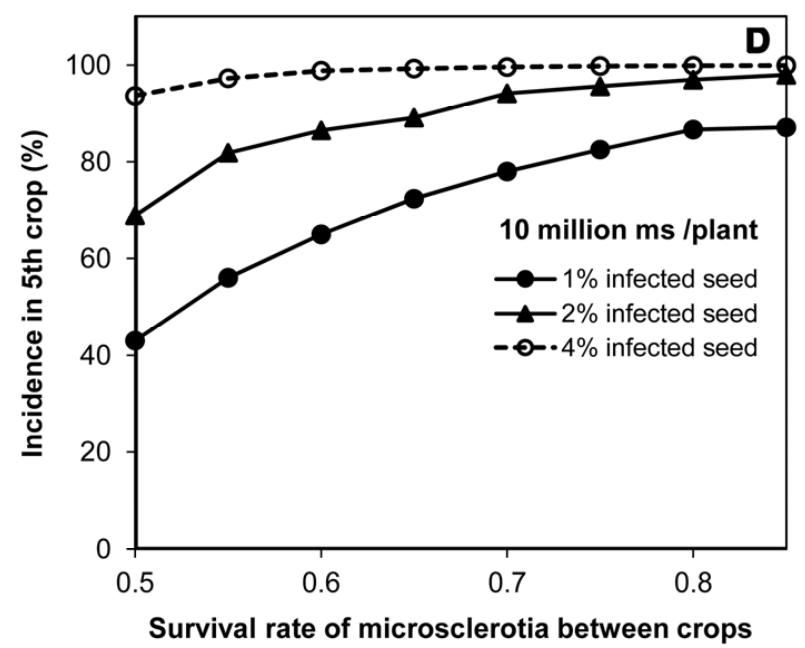

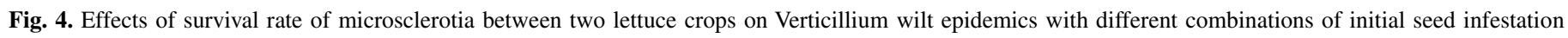
levels and number of microsclerotia formed on each diseased plant. Each data point in the figure represents the mean of five simulations. 
becomes more prominent when the incidence approaches $100 \%$ (Fig. 4D).

Responses to ID-DI curve parameters. The ID-DI relationship is very important to epidemics of Verticillium wilt in lettuce. Both ID-DI parameters affect the epidemics as expected. As the rate parameter $r$ increases, incidence of wilt increases rapidly, and as the threshold parameter $a$ increases, the epidemics of Verticillium wilt decelerate (Fig. 5). Generally, the minimum rate, $r$, required for an epidemic or for the establishment of the disease increases as the threshold, $a$, increases (Fig. 5). The response surface also changes with other factors such as the survival rate of microsclerotia and number of microsclerotia produced on each diseased plant.

Responses to the dispersal gradient parameters. Dispersal gradient affects the disease spread in two different ways. First, with a more aggregated (steeper) dispersal pattern, the microsclerotia newly produced on diseased plants remain mostly around the diseased plants. Therefore, the local inoculum density around the diseased plant can be higher than the threshold required to cause disease in the subsequent crops. Thus, a steeper gradient facilitates the establishment of the disease in a new field whereas a long-tail dispersal gradient could dilute inoculum density. When the initial seed infestation level is $2 \%$ and the number of microsclerotia produced on each diseased plant is 2.0 million with a survival rate at 50 or $85 \%$, or 5.0 million with a survival rate of $50 \%$, the decrease in the slope of the dispersal gradient can result in slowing down the disease or even the discontinuation of the disease epidemics (Fig. 6A to C). Second, a long-tail dispersal gradient allows microsclerotia produced on a diseased plant to be dispersed over a long distance; therefore, it promotes the spread of the disease in a field. When the number of microsclerotia produced on each diseased plant is high, dispersal of newly produced microsclerotia becomes more important to the spread of the disease than keeping inoculum density high enough for infection. Under a combination of 5 million microsclerotia/ plant with a survival rate of $85 \%$ and $2 \%$ of initial seed infestation, the decrease in dispersal gradient resulted initially in an increase in the rate of pathogen spread and higher disease incidence in the fifth lettuce crop. However, subsequent decrease in gradients again decelerated the disease progress, and a rapid disease spread was achieved by balancing these two effects. Thus, disease incidence peaked at moderate dispersal gradients (Fig. 6D).

Responses to the initial seed infestation levels. Initial infestation rate commonly affects the time when the disease incidence reaches a certain threshold (data not shown). When wilt incidence in the fifth lettuce crop is plotted against the initial seed infestation level, wilt incidence increases with the increase of initial seed infestation level (Fig. 7). In some cases, even when the initial seed infestation level is as low as $0.1 \%$, the disease incidence in
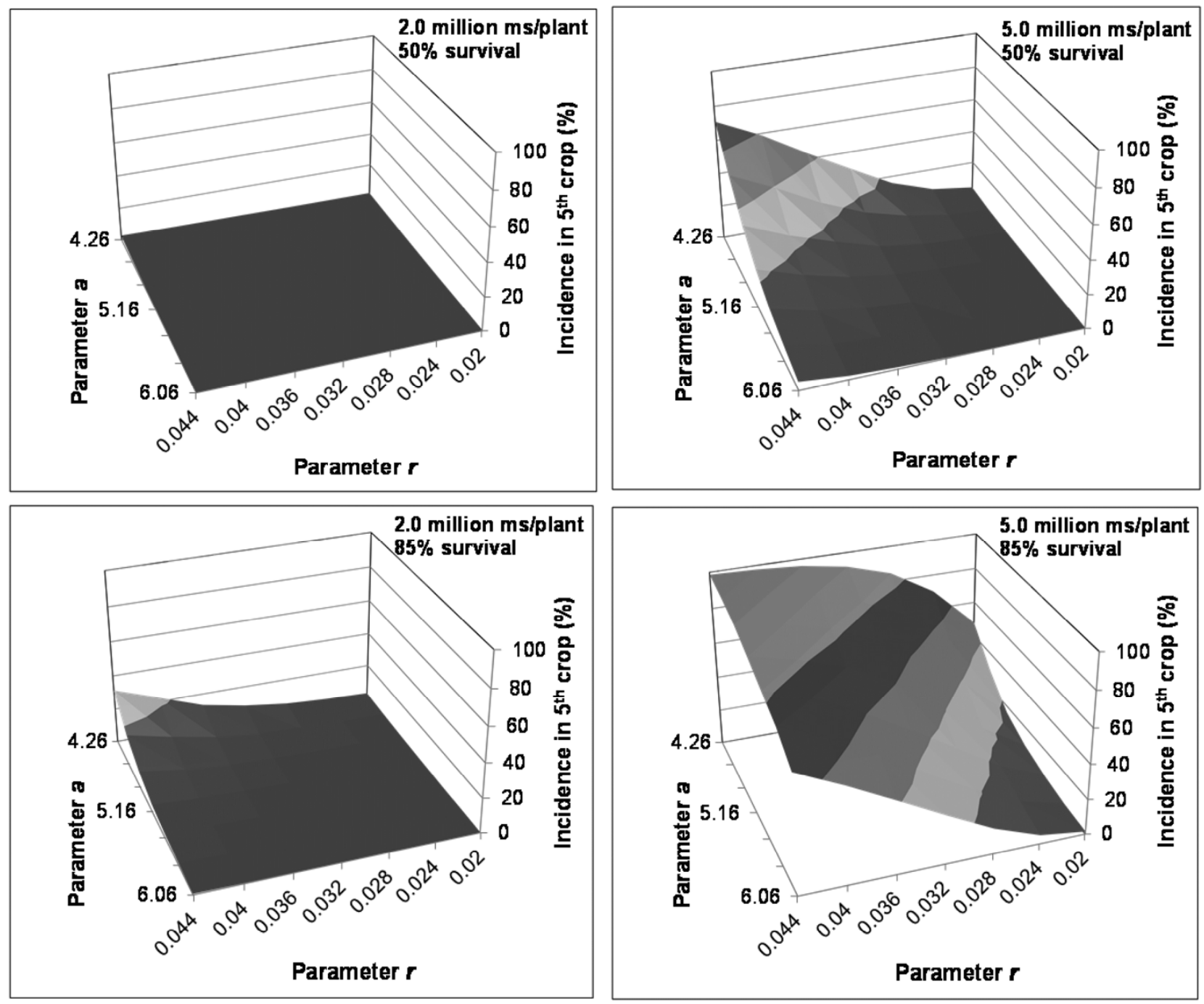

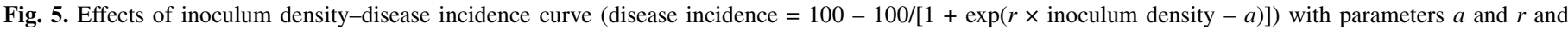

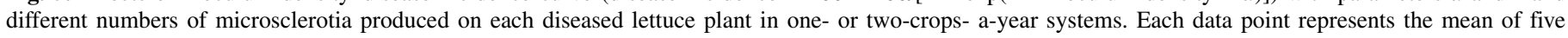
simulations. 
the fifth lettuce crop can still be considerable, reaching 1.27, 1.33, and $11.9 \%$ when 5.0 million microsclerotia are produced per diseased plant in combination with either a steep dispersal gradient (Fig. 7A), a high microsclerotia survival rate (85\%) between lettuce crops (Fig. 7D), or a combination of both (Fig. 7C), respectively. With the combination of low microsclerotial survival rate of 50\% and less-steep dispersal gradient, however, even when the pathogen forms 5.0 million microsclerotia/diseased plant, the disease level remains $<1.0 \%$ up to the fifth lettuce crop even when seed infestation level is at $3.2 \%$ (Fig. 7B). Under these conditions, seed with low infestation level would prevent the inoculum buildup. When the pathogen forms only 2.5 million microsclerotia/diseased plant, as long as the high survival rate is not in combination with steep dispersal gradient (Fig. 7C), seed with a low infestation level will also not lead to high wilt incidence on lettuce (Fig. 7A, B, and D). In summary, of the three factors (microsclerotia production per diseased plant, slope of the dispersal gradients, and survival rate of microsclerotia between lettuce crops), if two of the three or all three are low, then seed with a low infestation level is safe and seed infestation thresholds can be established.

\section{DISCUSSION}

Simulation models are generally goal oriented, inductive, and data dependent, with complex structures and multiple variables. Early simulation models (44) compartmentalized various components of the pathogen life cycles, and a majority of them relied on the differential equations to describe the change of pathogen or disease attributes. Subsequent simulation models developed in plant pathology adapted linked differential equations to describe the dynamics of plant diseases $(24,27)$. Among the best examples of previous simulation models that have had an impact on practical disease management is EPIPRE (34), which modeled the interaction of winter wheat, certain wheat pathogens, and cereal aphids. The only known simulation model developed for Verticillium wilt has been on cotton and is a deterministic, discrete plantpopulation model created by Gutierrez et al. (19). This provided the basis for modeling the effects of Verticillium wilt on cotton growth, development, and yield.

Interestingly, none of the simulation models developed in plant pathology account for the introduction of primary inoculum through seed or the duration over which this inoculum could increase to threaten crops as influenced by the cropping patterns of the area. Nor are the inoculum thresholds above which the disease develops incorporated in a simulation model. Verticillium wilt of lettuce is unique in many ways. A majority of U.S. lettuce production is concentrated in California, with central coastal California accounting for nearly $60 \%$ of the U.S. total (3). The crop had remained immune to Verticillium wilt through much of the 20th century, despite the pathogen affecting other crops in central coastal California. The sudden development of Verticillium wilt on lettuce in 1995 was puzzling but recent analyses of the pathogen populations from spinach seed and diseased lettuce have clearly established that migrant populations brought on spinach seed and the coincident expansion of spinach production are reasons for the new disease on lettuce $(3,4)$. Because the major avenue of introduction of the pathogen is through infested seed (lettuce or spinach) planted in the area, it was important to determine the minimum seed infestation levels required for Verticillium wilt development on lettuce, the duration over which Verticillium wilt appears on lettuce given that seedlots with different $V$. dahliae infestation levels are planted in the area, how the differing lettuce production patterns (one crop per year versus
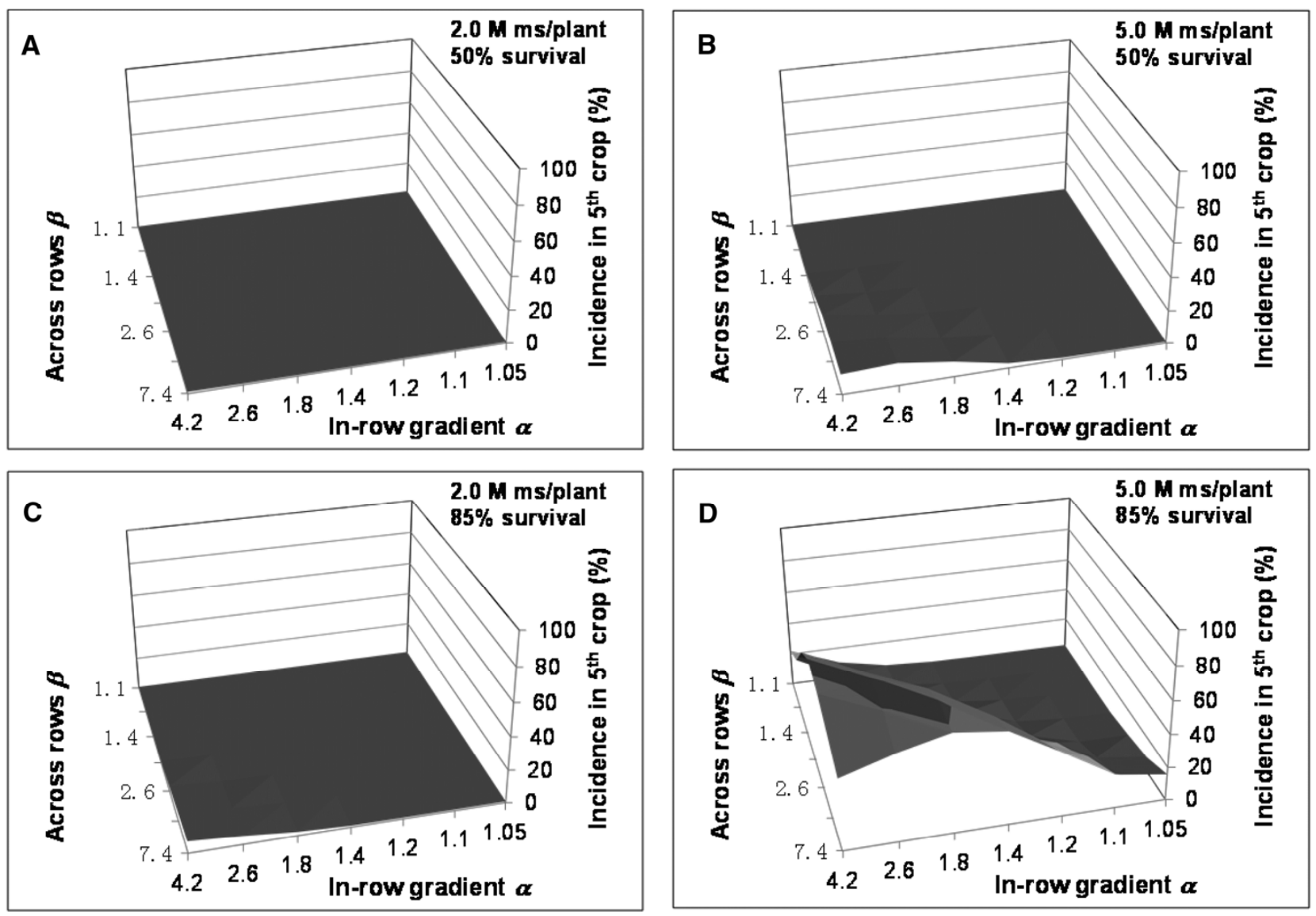

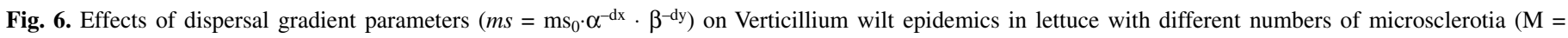
million) formed per plant and cropping systems (survival rates of microsclerotia between crops). 
two crops per year) would affect the duration over which the inoculum could reach levels to cause epidemics on lettuce, and so on. Field experimentation to obtain results for all these scenarios would take many years; in addition, conducting these experiments in grower's fields over many years and manipulating the multiple factors involved is a near impossibility. The approach we took in this study was to establish a framework for Verticillium wilt with a known source of inoculum that is being introduced through seed. Data collected over multiple years since the initial discovery of the disease on lettuce was instrumental in assembling this simulation model.

The simulation results confirmed the not-so-surprising importance of avoiding consecutive lettuce crops in the same field year after year (38). Assuming that the survival of microsclerotia is independent of their preceding history, according to the formula (2), if $S_{2 a}=S_{2 b}=85 \%$ and $S_{c}=75 \%$, then $S_{1}$ would be 0.541 . The results from a simulation based on survival rate at 55 and $85 \%$ revealed that this difference in survival rate of microsclerotia between lettuce crops could result in very different outcomes of disease spread and the rate at which inoculum density increases in the soil. Under certain conditions, such as the moderate levels of microsclerotia produced per diseased plant ( 2 to 2.5 million), the disease could seldom become established in a one-lettuce cropper-year system, in contrast to severe wilt epidemics on lettuce within just 2 to 3 years (as few as five crops total) in a two-cropsper-year system, with all other conditions being the same.

The results from this simulation study also revealed the importance of breeding resistance against $V$. dahliae in lettuce cultivars.
Partial resistance in the lettuce cultivars that reduces the number of microsclerotia formed on each diseased plant can also be valuable in the management of Verticillium wilt. Even though this kind of resistance is incomplete and allows the development of wilt symptoms and reproduction of microsclerotia to some extent, it can dramatically slow down the spread of Verticillium wilt in the field and sometimes prevent the establishment of the pathogen completely as long as it can reduce the microsclerotia formation by $60 \%$, from 5 million microsclerotia/plant to $<2.0$ million microsclerotia/plant. In the case of resistant and susceptible lettuce La Brillante and Salinas (43), respectively, the $>50$-fold difference (4.5 and 7.6 in La Brillante versus 513 and 1023 in Salinas) in the production of microsclerotia per gram of tissue of infected taproots would probably make Verticillium wilt unlikely to attain high incidence on resistant La Brillante.

One of the initial goals of this study was to establish a tentative threshold of seed infestation for the seed industry to ensure seed safety. The simulation results, however, revealed that, in most cases, the low seed infestation rate could only slow or delay the establishment of the pathogen; the pathogen would eventually become established if susceptible lettuce cultivars were grown in the field for many years. Only in cases when two of the three drivers such as low microsclerotia production per diseased plant, flat slope of dispersal gradient, and low survival rate of microsclerotia between lettuce crops are present, as influenced by (i) partially resistant lettuce cultivars, (ii) thorough tillage, and (iii) a one-crop-per-year or less frequent lettuce-cropping system, can a threshold for seed infestation be established. In the presence of
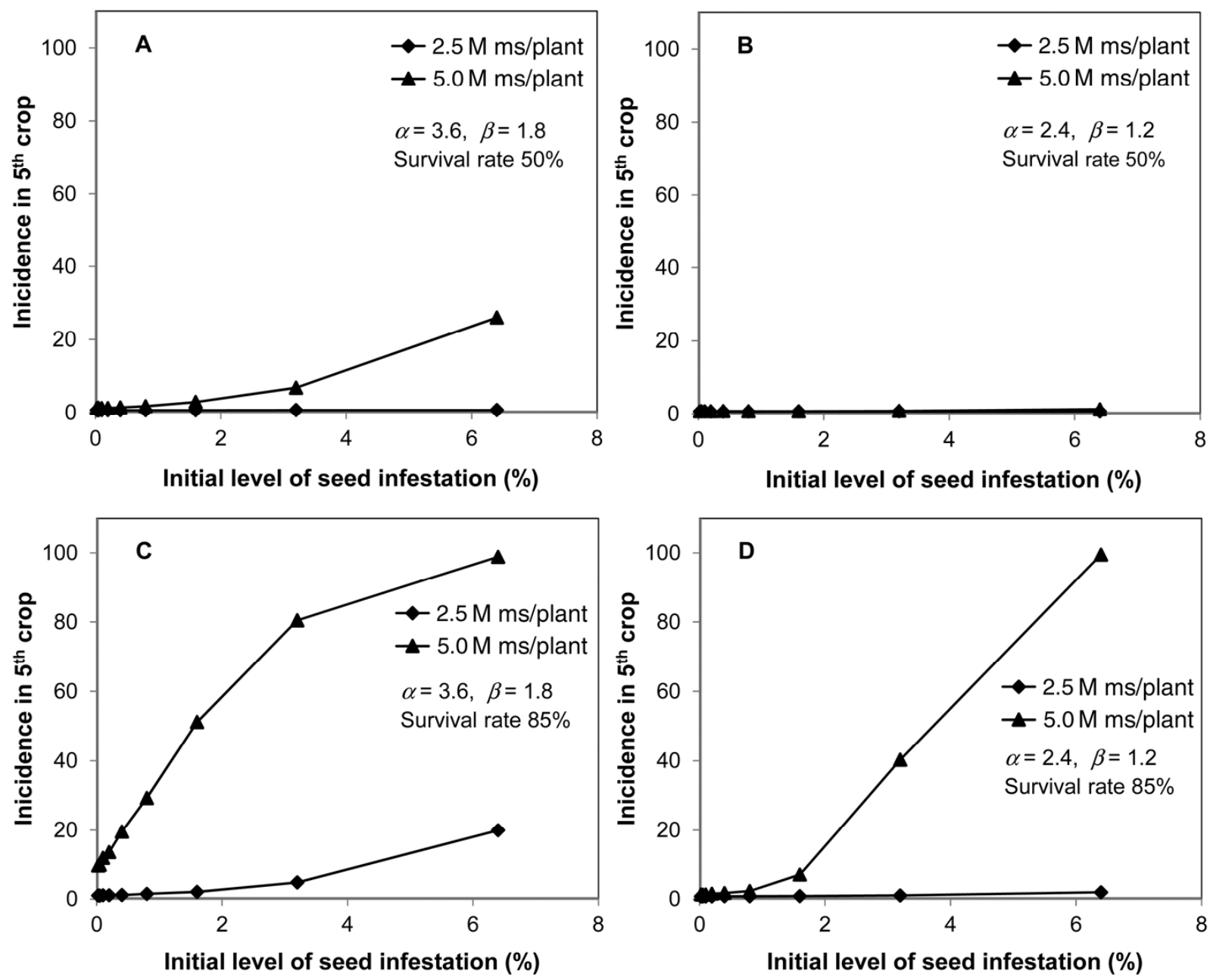

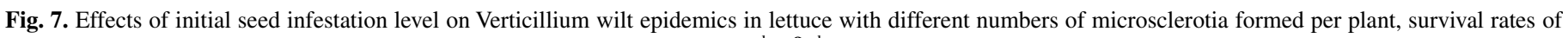
microsclerotia between crops, and dispersal gradients parameters $\left(m s=\mathrm{ms}_{0} \cdot \alpha^{-\mathrm{dx}} \cdot \beta^{-\mathrm{dy}}\right)$. 
two or more of these factors, $\leq 1 \%$ seed infestation can be considered safe and will not result in the establishment of the pathogen in soil or development of Verticillium wilt on lettuce crops.

The model developed in this study is likely a simplified reflection of the reality in many aspects. The conclusions drawn based on the results from this model may change as additional factors that influence the disease are considered. The model nonetheless provides a snapshot of the role played by seedborne inoculum in the establishment of the pathogen and the development of Verticillium wilt epidemics on lettuce under the parameters considered in this model. Among the factors not considered in the current simulation model are, first, the effects of environmental conditions that influence the disease. In reality, weather conditions affect all phases in the disease cycle, including infection, symptom development, production, and dispersal of microsclerotia. However, variations in time of infection could easily be incorporated as a further random variable in the model based on either an assumed distribution or from suitable observations. In nature, infections of lettuce plants do not occur at the same time, and the timing of infection may be very important for production, survival, and dispersal of microsclerotia. For example, if a plant is infected early in the seedling stage and dies before attaining the usual plant size, fewer microsclerotia are formed relative to a plant that is infected late and develops symptoms close to maturity. This simulation model also didn't consider long-distance (across 30 plants or farther) dispersal, resulting from surface running water, soil carried by farming equipment, and so on, in which the dispersal gradient may not follow a continuous curve. Although Verticillium epidemics below the threshold of 150 microsclerotia $\mathrm{g}^{-1}$ of soil have seldom occurred in lettuce production, the more critical factor determining whether the disease develops on individual plants is the minimum number of microsclerotia in the rhizosphere of these plants. This information is currently unavailable and is likely to be significantly greater for lettuce than for other hosts. The unlikely development of the disease on lettuce under the very low microsclerotial densities introduced by infested lettuce seed was not considered in this simulation and is also likely to be one of the limitations of the model. As this information becomes available, however, the model assumptions can be tested further.

We believe that this study is the first to present a framework for investigating the spread of seedborne diseases in a field. Because characteristics of Verticillium wilt in lettuce may also be observed in other disease systems, the information generated from this simulation study is likely to be useful in understanding the spread of other soilborne diseases. With some modifications, the model can be adapted to other disease problems, especially for those fungal pathogens that survive in soil and whose inoculum densities build up over multiple crops of the host plant.

\section{LITERATURE CITED}

1. Ashworth, L., Jr., Huisman, O., Harper, D., Stromberg, L., and Bassett, D. 1979. Verticillium dahliae wilt disease of cotton: Influence of inoculum density in the field. Phytopathology 69:483-489.

2. Ashworth, L., Jr., McCutcheon, O., and George, A. 1972. Verticillium albo-atrum: the quantitative relationship between inoculum density and infection of cotton. Phytopathology 62:901-903.

3. Atallah, Z. K., Hayes, R. J., and Subbarao, K. V. 2011. Fifteen years of Verticillium wilt of lettuce in America's salad bowl: A tale of immigration, subjugation, and abatement. Plant Dis. 95:784-792.

4. Atallah, Z. K., Maruthachalam, K., Toit, L. d., Koike, S. T., Michael Davis, R., Klosterman, S. J., Hayes, R. J., and Subbarao, K. V. 2010. Population analyses of the vascular plant pathogen Verticillium dahliae detect recombination and transcontinental gene flow. Fungal Genet. Biol. 47:416-422.

5. Berbegal, M., Ortega, A., García-Jiménez, J., and Armengol, J. 2007. Inoculum density-disease development relationship in Verticillium wilt of artichoke caused by Verticillium dahliae. Plant Dis. 91:1131-1136.
6. Brandt, W., Lacy, M., and Horner, C. 1984. Distribution of Verticillium in stems of resistant and susceptible species of mint. Phytopathology 74:587-591.

7. Butterfield, E., and DeVay, J. 1977. Reassessment of soil assays for Verticillium dahliae. Phytopathology 67:1073-1078.

8. Campbell, C. L., and Madden, L. V. 1990. Introduction to Plant Disease Epidemiology. John Wiley \& Sons, New York.

9. Carlstrom, R. C. 1969. Survival of Verticillium dahliae in soil. Ph.D. dissertation, Oregon State University, Corvallis.

10. du Toit, L. J., Derie, M. L., and Hernandez-Perez, P. 2005. Verticillium wilt in spinach seed production. Plant Dis. 89:4-11.

11. Erwin, D., Tsai, S., and Khan, R. 1978. Reduced number of microsclerotia formed by Verticillium dahliae in cotton tissue exposed to systemic benzimidazole fungicides and desiccation. Phytopathology 68: 1488-1494.

12. Farley, J., Wilhelm, S., and Snyder, W. 1971. Repeated germination and sporulation of microsclerotia of Verticillium albo-atrum in soil. Phytopathology 61:260-264.

13. Fradin, E. F., and Thomma, B. P. 2006. Physiology and molecular aspects of Verticillium wilt diseases caused by V. dahliae and V. albo-atrum. Mol. Plant Pathol. 7:71-86.

14. Friebertshauser, G., and DeVay, J. 1982. Differential effects of the defoliating and nondefoliating pathotypes of Verticillium dahliae upon the growth and development of Gossypium hirsutum. Phytopathology 72:872877.

15. Gilligan, C. A., and van den Bosch, F. 2008. Epidemiological models for invasion and persistence of pathogens. Annu. Rev. Phytopathol. 46:385418.

16. Green, R. J., Jr. 1980. Soil factors affecting survival of microsclerotia of Verticillium dahliae. Phytopathology 70:353-355.

17. Grogan, R., Ioannou, N., Schneider, R., Sall, M., and Kimble, K. 1979. Verticillium wilt on resistant tomato cultivars in California: Virulence of isolates from plants and soil and relationship of inoculum density to disease incidence. Phytopathology 69:1176-1180.

18. Gutierrez, A., and DeVay, J. 1986. Studies of plant-pathogen-weather interactions: cotton and Verticillium wilt. Pages 205-231 in: Plant Disease Epidemiology: Population Dynamics and Management. K. J. Leonard and W. E. Fry, eds. Macmillan Publishing Co., New York.

19. Gutierrez, A., Falcon, L., Loew, W., Leipzig, P., and Bosch, R. 1975. An analysis of cotton production in California: A model for Acala cotton and the effects of defoliators on its yields. Environ. Entomol. 4:125-136.

20. Harris, D., and Yang, J. 1996. The relationship between the amount of Verticillium dahliae in soil and the incidence of strawberry wilt as a basis for disease risk prediction. Plant Pathol. 45:106-114.

21. Hawksworth, D., and Talboys, P. 1970. Verticillium nubilum. Vol. 258, CMI Descriptions of Pathogenic Fungi and Bacteria. Commonwealth Mycological Institute, Kew, UK.

22. Inderbitzin, P., Bostock, R. M., Davis, R. M., Usami, T., Platt, H. W., and Subbarao, K. V. 2011. Phylogenetics and taxonomy of the fungal vascular wilt pathogen Verticillium, with the descriptions of five new species. PLoS One 6:e28341.

23. Isaac, I., and Harrison, J. 1968. The symptoms and causal agents of early dying disease (Verticillium wilt) of potatoes. Ann. Appl. Biol. 61:231-244.

24. Jeger, M. 1986. The potential of analytic compared with simulation approaches to modeling in plant disease epidemiology. Pages 255-281 in: Plant Disease Epidemiology: Population Dynamics and Management. K. J. Leonard and W. E. Fry, eds. Macmillan Publishing Co., New York.

25. Johnson, D. A., Zhang, H., and Alldredge, J. R. 2006. Spatial pattern of Verticillium wilt in commercial mint fields. Plant Dis. 90:789-797.

26. Kalb, D., and Millar, R. 1986. Dispersal of Verticillium albo-atrum by the fungus gnat (Bradysia impatiens). Plant Dis. 70:752-753.

27. Madden, L. V., Hughes, G., and van den Bosch, F. 2007. The Study of Plant Disease Epidemics. American Phytopathological Society, St. Paul, $\mathrm{MN}$.

28. McIntyre, J. L., and Horner, C. E. 1973. Inactivation of Verticillium dahliae in peppermint stems by propane gas flaming. Phytopathology 63:172-175.

29. Mol, L., and Scholte, K. 1995. Formation of microsclerotia of Verticillium dahliae Kleb. on various plant parts of two potato cultivars. Potato Res. 38:143-150.

30. Nicot, P., and Rouse, D. 1987. Relationship between soil inoculum density of Verticillium dahliae and systemic colonization of potato stems in commercial fields over time. Phytopathology 77:1346-1355.

31. Pegg, G. F., and Brady, B. L. 2002. Verticillium Wilts. CABI Publishing, New York.

32. Powelson, M. L., and Rowe, R. C. 1993. Biology and management of early dying of potatoes. Annu. Rev. Phytopathol. 31:111-126.

33. Pullman, G., and DeVay, J. 1982. Epidemiology of Verticillium wilt of cotton: A relationship between inoculum density and disease progression. Phytopathology 72:549-554. 
34. Rabbinge, R., and Rijsdijk, F. 1983. EPIPRE: A disease and pest management system for winter wheat, taking account of micrometeorological factors. EPPO Bull. 13:297-305.

35. Roget, D. 2001. Prediction modelling of soilborne plant diseases. Australas. Plant Pathol. 30:85-89.

36. Rowe, R. C., and Powelson, M. L. 2002. Potato early dying: Management challenges in a changing production environment. Plant Dis. 86:11841193.

37. Schnathorst, W. C. 1981. Life cycle and epidemiology of Verticillium. Pages 81-111 in: Fungal Wilt Diseases of Plants. M. E. Mace, A. A. Bell, and C. H. Beckman, eds. Academic Press, New York.

38. Shipton, P. 1977. Monoculture and soilborne plant pathogens. Annu. Rev. Phytopathol. 15:387-407.

39. Subbarao, K. V., Hubbard, J. C., Greathead, A. S., and Spencer, G. A. 1997. Verticillium wilt. Pages 26-27 in: Compendium of Lettuce Diseases. R. M. Davis, K. V. Subbarao, R. N. Raid, and E. A. Kurtz, eds. American Phytopathological Society, St. Paul, MN.

40. Tjamos, E. C., Rowe, R. C., Heale, J. B., and Fravel, D. R. 2000. Advances in Verticillium Research and Disease Management. American Phytopathological Society, St. Paul, MN.

41. Usami, T., Kanto, T., Inderbitzin, P., Itoh, M., Kisaki, G., Ebihara, Y., Suda, W., Amemiya, Y., and Subbarao, K. V. 2011. Verticillium tricorpus causing lettuce wilt in Japan differs genetically from California lettuce isolates. J. Gen. Plant Pathol. 77:17-23.

42. Vallad, G. E., Bhat, R. G., Koike, S. T., Ryder, E. J., and Subbarao, K. V. 2005. Weedborne reservoirs and seed transmission of Verticillium dahliae in lettuce. Plant Dis. 89:317-324.

43. Vallad, G., and Subbarao, K. 2008. Colonization of resistant and susceptible lettuce cultivars by a green fluorescent protein-tagged isolate of Verticillium dahliae. Phytopathology 98:871-885.

44. Waggoner, P. E. 1978. Computer simulation of epidemics. Pages 203-222 in: Plant Disease: An Advanced Treatise, Vol. 2: How Disease Develops in Populations. J. G. Horsfall and E. B. Cowling, eds. Academic Press, Inc., New York.

45. Wilhelm, S. 1955. Longevity of the Verticillium wilt fungus in the laboratory and field. Phytopathology 45:180-181.

46. Wilhelm, S., and Paulus, A. O. 1980. How soil fumigation benefits the California strawberry industry. Plant Dis. 64:264-270.

47. Xiao, C. L., and Subbarao, K. 1998. Relationships between Verticillium dahliae inoculum density and wilt incidence, severity, and growth of cauliflower. Phytopathology 88:1108-1115.

48. Xiao, C. L., Hao, J., and Subbarao, K. 1997. Spatial patterns of microsclerotia of Verticillium dahliae in soil and Verticillium wilt of cauliflower. Phytopathology 87:325-331. 